\title{
A Five-Year Retrospective Study of Gestational Trophoblastic Disease at University of Maiduguri Teaching Hospital Maiduguri, Nigeria
}

\author{
Obetta Hillary Ikechukwu ${ }^{1}$, Hadiza Abdullah Usman ${ }^{1}$, \\ Nweze Sylvester Onuegunam ${ }^{2}$, Ezenwaeze Malachy Nwaeze
}

\begin{abstract}
${ }^{1}$ Department of Obstetrics and Gynaecology, University of Maiduguri Teaching Hospital, Maiduguri, Nigeria ${ }^{2}$ Department of Obstetrics and Gynaecology, ESUT College of Medicine/Teaching Hospital, Parklane, GRA, Enugu, Nigeria
\end{abstract}

Corresponding Author: Ezenwaeze Malachy Nwaeze

\begin{abstract}
Background: Gestational trophoblastic disease (GTD) is an uncommon complication of pregnancy. It is of clinical and epidemiological interest partly because of its good prognosis if detected and managed early. Objective: This study was to determine the prevalence, clinical presentation, management outcome and histologic types of GTDs at University of Maiduguri Teaching Hospital, Maiduguri, Nigeria.
\end{abstract}

Methodology: A five-year retrospective study of histologically confirmed cases of GTDs managed in UMTH was undertaken. Folders of patient treated for GTD during the study period served as source of data. Statistical analysis was done using Statistical Package for the Social Sciences.

Results: There were a total of 47 (38 molar and 9 choriocarcinoma) cases of GTDs that were diagnosed and managed at UMTH. However, only $40[31(77.5 \%)]$ molar and $[9(22.5 \%)$ choriocarcinoma] case files were retrieved. $55 \%$ of the GTDs were complete hydatidiform mole, $22.5 \%$ partial hydatidiform mole and $22.5 \%$ choriocarcinoma. There was no case of invasive mole or placental site trophoblastic tumour noted. There were 15,426 deliveries in UMTH during this period giving the incidence of GTDs as 3.0 per 1000 deliveries or 1 in 328deliveries. The mean (SD) age of the patients was $30.5 \pm$ 5.6years. Only $3(7.5 \%)$ of the patients were below 20 years of age and those who were at least 40 years of age constituted $8(20 \%)$. Low parity constituted $62.5 \%$ of the patients while
$12.5 \%$ and $2.5 \%$ were nullipara and primipara respectively. The mean gestational age (SD) at presentation was $16.5 \pm 6.2$ weeks. The common clinical presentations were amenorrhoea (100.0\%), abnormal vaginal bleeding (97.5\%), lower abdominal pain (90\%) and passage of grape-like vesicles (45.0\%). Only 6(15.0\%) complied with the follow-up protocol for one year, while $25(62.5 \%)$ of the patients did not observe the follow-up protocol. Anaemia was the commonest complication observed.

Conclusion: Gestational trophoblastic disease is relatively common in our center with an incidence of 3.0 per 1000 deliveries and 1.48\% of our gynaecological admissions. Adequate patient counseling and compliance to follow-up are recommend for good outcome.

Keywords: Prevalence, gestational trophoblastic disease, Hydatidiform mole, Choriocarcinoma, Maiduguri

\section{INTRODUCTION}

Gestational trophoblastic disease (GTD) describes a group of inter-related diseases, including the premalignant disorders of partial and complete hydatidiform mole (PHM and CHM) and the malignant disease of invasive mole, choriocarcinoma and the rare placental site trophoblastic tumour/epitheloid trophoblastic tumour (PSTT/ETT). ${ }^{1}$ The malignant diseases are also collectively named gestational trophoblastic neoplasia (GTN). ${ }^{1-}$

The World Health Organization 
classification of GTD includes hydatidiform mole (partial and complete), invasive mole, choriocarcinoma, persistent trophoblastic disease and placental site trophoblastic tumour ${ }^{4}$. Gestational trophoblastic diseases (GTDs) are composed of syncytiotrophoblastic and cytotrophoblastic cells, with the exception of PSTT, which is derived from intermediate trophoblastic cells. ${ }^{1-4}$ In addition to being the first and only disseminated solid tumours that has proved to be highly curable by chemotherapy, they also produce unique and characteristic tumour marker, human chorionic gonadotropin (hCG). ${ }^{1,3-5}$ Albeit persistent GTD most commonly follows a molar pregnancy, it can be seen after any type of gestation, including term pregnancy, abortion and ectopic pregnancy ${ }^{1,2}$.

The incidence of GTD varies in different regions of the world. ${ }^{5-10}$ The incidence of molar pregnancies in the United States is 1 per 1000 pregnancies, in the United Kingdom 1.5 per 1000 pregnancies and in Japan 2 per $1000 .^{2}$ In Nigeria, incidencesof 3.8 per 1000 deliveries and 4.7 per 1000 deliveries were reported from North-west and South-east respectively $^{2}$. In general, areas with high incidence of molar pregnancies have proportionately greater incidence of choriocarcinoma arising from hydatidiform mole. ${ }^{2}$ Gestational Trophoblastic Disease (GTD) has been reported to have the highest incidence in Africa and Asia. ${ }^{10}$

Complete mole, which is genetically $46 \mathrm{XX}$, results from the fertilization of an empty ovum by a haploid sperm followed by duplication or dispermy 46XY (fertilization of an empty ovum by two different sperm) . 1, 3, 4,8 On the other hand, partial mole is usually due to triploidy (69XXY, 69XXX, 69XYY) ${ }^{1,4,8}$ The hydatidiform mole (HM) is characterized pathologically by a bunch of grape-like structures with complete mole having hydropic villi, trophoblastic hyperplasia and absent embryo and the partial mole having hydropic villi and fetal parts.$^{1,4,8,9}$ The invasive mole is locally invasive and is usually diagnosed due to persistent hCG following approximately $5-10 \%$ of all molar pregnancies. ${ }^{4}$ Pathologically, molar changes are seen penetrating the myometrium on hysterectomy specimen or ultrasound. ${ }^{4}$ It is a cause of acute abdomen, haemorrhage and uterine perforation ${ }^{4}, 8,9,11$ Placental site trophoblastic tumour (PSTT)arises from the placental bed mostly from the intermediate mesoderm, usually following a term pregnancy. ${ }^{1,3,4}$ It may be benign or malignant, secrets low amount of hCG but high amount of human placental lactogen (hPL) and as such, it is not chemosensitive - 4,8,9,12 It rarely metastasizes beyond the uterus $^{4,8,9,12,13}$ and predominantly occurs after delivery of a female infant. ${ }^{9}$ Fifty percent of chorioccarcinoma follows hydatidiform mole, whereas abortion and term pregnancy contribute $25 \%$ each . , $8,11,14$ It secrets large amounts of hCG 100,000 to 400,000 units daily causing theca lutein cysts $^{8}$. Some cases of choriocarcinoma (non-gestational choriocarcinoma) have been known to arise de novo as a germ cell tumour. ${ }^{15}$

Patients with hydatidiform mole usually present with history of amenorrhoea, vaginal bleeding and spontaneous passage of grape-like vesicles. ${ }^{2,3,4,6,8,9,16-22}$ Molar pregnancy usually presents in the $4^{\text {th }}$ and $5^{\text {th }}$ month of pregnancy and should be suspected in any woman with vaginal bleeding in the first half of pregnancy ${ }^{4}$ occurring in up to $92 \%$ of cases, ${ }^{4,8}$ and passage of vesicles in $60 \%$ of patients. ${ }^{4}$ Other rare presentations are hyperemesis gravidarum, pre-eclampsia, hyperthyroidism and symptomatic thecalutein cysts.5 These clinical features typically occur in patients who do not have early prenatal care and present at advanced gestational ages with markedly elevated serum B-hCG levels. ${ }^{5}$ The absence of fetal heart tones, a uterus too large for the estimated gestational age and the presence of theca lutein cysts on physical examination further support the diagnosis. ${ }^{4,5}$ However, ultrasonography which shows classic "snowstorm" appearance is a reliable 
and sensitive technique for pre-evacuation diagnosis but the definitive diagnosis is made on histological examination of the products of conception. ${ }^{2,3,4,5,10,20}$

In the management of GTDs, treatment depends on the histological type. Suction evacuation is the most common form of management for hydatidiform mole. 2,4,8,12,20,22 Other modes of treatment include chemotherapy, hysterectomy and radiotherapy or a combination of these. , $^{4,8}$ However, the Royal College of Obstetricians and Gynaecologists recommends that suspected complete molar pregnancies should be treated by suction evacuation, while suspected partial molar pregnancies should generally be treated by medical termination as the fetal parts can present an obstacle to suction evacuation. ${ }^{21}$ The complications of GTD include haemorrhage with its attendant consequences such as anaemia and shock, sepsis and metastasis to distant sites such as the lungs, liver and brain. $1,2,3,4,5,6,7,8,9,10$ Other complications include pulmonary embolism due to deportation of trophoblastic tissue to the lungs during suction evacuation or medical termination of pregnancy and drug resistance in cases of choriocarcinoma. ${ }^{8}$ Despite the excellent prognosis and potentials for fertility preservation following proper treatment and follow- up, ${ }^{1,4}$ study has shown that many of the patients with GTDs do not return for follow-up. ${ }^{4} \quad$ This study, therefore, sought to determine the prevalence, clinical presentation, management and histological types of gestational trophoblastic disease in our centre.

\section{MATERIALS AND METHODS}

This was a retrospective study of patients who were managed for gestational trophoblastic disease (GTD) in the Department of Obstetrics and Gynaecology, University of Maiduguri Teaching Hospital over a five-year period from $1^{\text {st January }} 2012$ to $31^{\text {st }}$ December, 2016. Ethical approval was obtained from the ethics committee of the hospital for the conduct of the research.
Histologically confirmed cases of GTDs were extracted from the histopathology department's records and their case records were retrieved from the medical records department of the hospital with retrieval rate of $85.1 \%$ (40/47 files).Relevant information extracted from these folders included age, ethnic group, educational qualification, parity, presenting symptoms, gestational age at presentation, investigations carried out, mode of treatment, complications, follow-up evaluation, outcome of treatment and histological type of the GTDs. The gynaecological ward and labour ward registers provided vital information on the total number of admissions and deliveries respectively within the period under review. The data processing and analysis were carried out using the Statistical Package for the Social Sciences software version 23.0 (Armonk New York: IBM Corp. 2015) and presented in tabular form using frequencies, percentages, means and standard deviations.

\section{RESULTS}

During the study period, there were 47 (38 molar and 9 choriocarcinoma) cases of GTDs that were diagnosed and managed at University of Maiduguri Teaching Hospital (UMTH). However, only 40 [31(77.5\%)] molar and [9(22.5\%) choriocarcinoma] case files were retrieved from the Medical Records Department of the hospital. There was no case of invasive mole or placental site trophoblastic tumour during the period under review. There were 15,426 deliveries in this centre during this period giving the incidence of GTDs as 3.0 per 1000 deliveries or lin 328 deliveries. Also there were 3,181 gynaecological admissions during the study period and hence GTDs constituted $1.48 \%$ of all gynaecological admissions during the period under review. The mean age of the patients was $30.5 \pm 5.6$ years with $60 \%$ within the age range of 20 to 34 years as shown in table 1. Table 1 has also demonstrated that Kanuri and Shuwa constituted $65.0 \%$ of the cases reviewed and that majority of the patients $(75 \%)$ had either primary or no 
basic education. Fifty percent of the patients reviewed were of low parity and $12.5 \%$ of the patients were nullipara while $72.5 \%$ of them presented in the second trimester as demonstrated in table 2 below. Table 3 has shown that abnormal vaginal bleeding was the commonest clinical feature and was seen in $97.5 \%$ of the cases reviewed. Suction evacuation was employed in the management of the 40 cases of GTD reviewed and anaemia was the commonest complication as shown in table 4 below. Table 5 has shown that $62.5 \%$ of the patients did not comply with the follow-up protocol while table 6 has revealed that $55 \%$ of the GTDs studied were complete hydatidiform mole.

Table 1: Socio-demographic characteristics of the $\mathbf{4 0}$ cases of GTDs

\begin{tabular}{|l|c|c|}
\hline \multicolumn{1}{|c|}{ Age (Years) } & Frequency & Percentage (\%) \\
\hline$<20$ & 3 & 7.5 \\
\hline $20-34$ & 24 & 60.0 \\
\hline$\geq 35 \quad$ Total & 13 & 32.5 \\
\hline \multicolumn{1}{|c|}{ Ethnic group } & Frequency & Percentage (\%) \\
\hline Kanuri & 18 & 45.0 \\
\hline Shuwa & 8 & 20.0 \\
\hline Hausa & 3 & 7.5 \\
\hline Igbo & 3 & 7.5 \\
\hline Yoruba & 2 & 5.0 \\
\hline Margi & 3 & 7.5 \\
\hline Babur/Bura & 1 & 2.5 \\
\hline Fulani $\quad$ Total & 2 & 5.0 \\
\hline & $\mathbf{4 0}$ & $\mathbf{1 0 0 . 0}$ \\
\hline Educational attainments & Frequency & Percentage (\%) \\
\hline Primary & 13 & 32.5 \\
\hline Secondary & 8 & 20.0 \\
\hline Tertiary & 2 & 5.0 \\
\hline None Total & 17 & 42.5 \\
\hline \multicolumn{2}{r|}{ T0 } & $\mathbf{1 0 0 . 0}$ \\
\hline
\end{tabular}

Table 2: Parity and gestational age distribution of cases of GTD patients

\begin{tabular}{|c|c|c|}
\hline Variables & Frequency & Percentage (\%) \\
\hline \multicolumn{3}{|l|}{ Parity } \\
\hline 0 & 5 & 12.5 \\
\hline $1-4$ & 20 & 50.0 \\
\hline$\geq 5$ & 15 & 37.5 \\
\hline Total & 40 & 100.0 \\
\hline \multicolumn{3}{|c|}{ Gestational Age (Weeks) } \\
\hline First trimester & 11 & 27.5 \\
\hline Second trimester & 29 & 72.5 \\
\hline Total & 40 & 100.0 \\
\hline
\end{tabular}

Table 3: Clinical features of 40 patients with GTD

\begin{tabular}{|l|c|c|}
\hline \multicolumn{1}{|c|}{ Variables } & Frequency & Percentage (\%) \\
\hline Abnormal vaginal bleeding & 39 & 97.5 \\
\hline Lower abdominal pain & 36 & 90.0 \\
\hline Passage of vesicles & 18 & 45.0 \\
\hline Vomiting & 3 & 7.5 \\
\hline
\end{tabular}

Some of the patients had more than one clinical feature

Table 4: Treatment Modality and Complications

\begin{tabular}{|l|c|c|}
\hline \multicolumn{1}{|c|}{ Treatment Modality } & Frequency & Percentage (\%) \\
\hline Suction evacuation & 40 & 100.0 \\
\hline Chemotherapy & 7 & 17.5 \\
\hline Hysterectomy & 3 & 7.5 \\
\hline Complications & Frequency & Percentage (\%) \\
\hline Anaemia & 34 & 85.0 \\
\hline Hypovolaemic shock & 6 & 15.0 \\
\hline Hyperemesis gravidarum & 5 & 12,5 \\
\hline Metastasis & 3 & 7.5 \\
\hline
\end{tabular}

Table 5: The Follow-up of the 40 patients with GTDs

\begin{tabular}{|c|c|c|}
\hline Duration of follow-up & Frequency & Percentage (\%) \\
\hline Less than 6 months & 9 & 22.5 \\
\hline 6-12 months & 6 & 15.0 \\
\hline Did not comply with follow-up & 25 & 62.5 \\
\hline Total & 40 & 100.0 \\
\hline
\end{tabular}

Table 6: Histologic variants of GTD seen in the study

\begin{tabular}{|l|c|c|}
\hline Histologic type & Frequency & Percentage (\%) \\
\hline Complete hydatidiform mole & 22 & 55.0 \\
\hline Partial hydatidiform mole & 9 & 22.5 \\
\hline Choriocarcinoma & 9 & 22.5 \\
\hline \multicolumn{1}{|c|}{ Total } & $\mathbf{4 0}$ & $\mathbf{1 0 0 . 0}$ \\
\hline
\end{tabular}

\section{DISCUSSION}

The incidence of GTD in this study is 3.0 per 1000 deliveries or 1 in 328 deliveries and this is lower than the previous incidences of 3.8 per 1000 , 4.7 per 1000 7.2 per 1000 and 5.7 per 1000 deliveries reported in Kano Nnewi, Zaria and Jos respectively. 2,4,6,22 However, this incidence is higher than those reported in developed societies such as United States of America and United Kingdom where incidences of 1 per 1000 pregnancies and 1.5 per 1000 pregnancies respectively have been reported. ${ }^{2}$ This is in agreement with the previous studies which have consistently shown that the incidence of GTDs is much higher in developing countries such as Nigeria than in developed societies. ${ }^{1,2,3}$ Also GTD has been reported to have the highest incidence in Africa and Asia. ${ }^{10}$ The plausible explanations for these wide variations in incidence may be as a result of ethnicity and lack of uniformity in histopathological reporting in different parts of the world.

Sixty per cent of the gestational trophoblastic diseases in this study occurred in women within the age range of 20-34 years which is within the peak of reproductive age of women in our setting. It 
also occurred most in women of low parity with $62.5 \%$ of the cases being para 4 and below; $12.5 \%$ of whom were primipara. This is, however, in sharp contrast with other studies which revealed a significant increase in the incidence of GTD at the extremes of reproductive ages and in women of high parity. ${ }^{1,3,4,5,6,20}$ The occurrence of GTDs in mostly women of low parity lends credence to the suggestion that parity per se may not be an independent risk factor in the epidemiology of GTDs, ${ }^{5}$ hence, the need for further studies to elucidate the cause of the variations among the women studied.

This study has also demonstrated that majority of the patients had no formal education $(42.5 \%)$ and this finding is in consonance with previous study done in Ilorin, Nigeria which revealed that $58.3 \%$ of the patients studied had no formal education or only acquired primary education. ${ }^{20}$ This high level of illiteracy among the subjects studied may partly explain the reason behind late presentation in this study since education has consistently been shown in literature to positively influence one's health seeking behaviour. This could explain the advanced gestational age at presentation with $55 \%$ of the cases presenting at 15 to 19 weeks' gestation.

This study has shown that majority of the patients $29(72.5 \%)$ managed presented in the second trimester of pregnancy while only $11(27.5 \%)$ presented in the first trimester. However, the converse is the case in developed societies where the practice of early localization and identification of pregnancy using transvaginal ultrasound scan has assisted in no small measure in early diagnosis of abnormal pregnancies and other related pathologies, hence, facilitating early diagnosis of gestational trophoblastic diseases at asymptomatic stage. ${ }^{1,5,8,11}$ This finding of late presentation in this study is in agreement with most of the previous studies carried out in resource-challenged societies such as Nigeria ${ }^{5,6,17}$. The likely explanation for the late presentation in poor resource settings may be due to poverty, ignorance, cultural beliefs, illiteracy and inadequate healthcare facilities which remain a common denominator in these settings. Kanuri and Shuwa are the 2 major ethnic groups in this region; therefore, their constitution of $67.5 \%$ of this study has no much epidemiological significance.

Abnormal vaginal bleeding and lower abdominal pain were the most common presenting symptoms and are similar to the findings in other studies. $^{2,5,6,16,18}$ Other symptoms include passage of grape-like vesicles $(45.0 \%)$ and vomiting (7.5\%). Symptoms of preeclampsia and hyperthyroidism were not found in this study but previous studies had documented that these disease conditions are relatively rare in GTDs. ${ }^{5,18}$

All the patients 40(100.0\%) had suction evacuation and chemotherapy was introduced following histologic diagnosis of choriocarcinoma as this was the preferred method of treatment in cases of suspected molar pregnancy. 1,3,5,6,8,11,13,20 Chemotherapy was used in the management of choriocarcinoma in $7(17.5 \%)$ of the patients while $3(7.5 \%)$ had hysterectomy. Two of the patients who had hysterectomy had completed their family size and one had the procedure done due to torrential haemorrhage following suction evacuation. Majority of the patients $34(85.0 \%)$ had anaemia defined as haemoglobin level < $10 \mathrm{~g} / \mathrm{dl}^{6}$ and $28(70.0 \%)$ of the patients had blood transfusion. This finding is in consonance with previous studies. ${ }^{6,7}$ Hypovolaemic shock and hyperemesis gravidarum were seen in $6(15.0 \%)$ and $5(12.5 \%)$ respectively. Metastasis was seen only in $3(7.5 \%)$ and all were detected in patients with choriocarcinoma. Albeit the Royal College of Obstetricians and Gynaecologists (RCOG) recommends that suspected complete molar pregnancies should be treated by suction evacuation, while suspected partial molar pregnancies should generally be treated by medical termination as the fetal part can present an obstacle to suction evacuation, ${ }^{21}$ the latter 
recommendation was, however, not employed in the management of the cases reviewed. No maternal death was recorded in the cases reviewed.

Furthermore, this study has shown that majority of the patients $25(62.5 \%)$ did not comply with the follow-up protocol and only $6(15.0 \%)$ adhered to the follow-up protocol for one year. This finding is consistent with previous documentations in

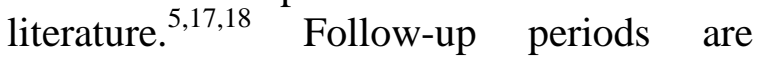
designed towards identifying any undesirable effects of treatment and early detection of relapse. ${ }^{5}$ However, the observation that a good number of patients in this study did not comply with the followup schedule certainly eliminated the window of opportunity for early detection of relapses. This study also demonstrated that $55.0 \%$ were complete hydatidiform mole, $22.5 \%$ were partial hydatidiform mole while $22.5 \%$ were choriocarcinoma. This finding is at variance with the earlier study conducted by Audu et al in this centre which revealed that partial mole occurred more frequently than complete hydatidiform mole. ${ }^{16}$ This finding is also at variance with the study conducted in Nnewi, Southeast Nigeria which revealed a higher incidence of choriocarcinoma. ${ }^{5}$

This study is limited in strength because the population studied was hospitalbased and may not be a true representative of the incidence of GTDs in the community. Besides, the data were collated retrospectively and this increased the chances of missing case files which further weakened the strength of the study.

\section{CONCLUSION}

Gestational trophoblastic disease is relatively common in our centre with an incidence of 3.0 per 1000 deliveries and $1.48 \%$ of our gynaecological admissions. Majority of the patients presented in the second trimester of pregnancy with anaemia being the commonest complication. Poor compliance with GTDs follow-up protocol was observed in this study and this calls for awareness creation amongst the patients and the populace if the complications associated with poorly managed GTDs are to be minimized.

Data Availability: All the necessary data are included in the manuscript

Conflict Of Interest: The authors declare that they have no conflict of interests.

Funding: There is no external source of fund outside the authors

Ethical Approval: Ethical approval for this study was gotten from the ethics committee of University of Maiduguri Teaching Hospital.

\section{ACKNOWLEDGMENTS}

Authors are grateful to the staff of Medical Record department, the special baby care unit (SBCU) staff, the Histopathology department and the Nurses in the labour ward who facilitated data collection for the conduct of this research.

\section{REFERENCES}

1. Froeling FEM, Seckel MJ. Gestational trophoblastic disease. In: Leusely DM Kilby MD. (eds). Obstetrics and Gynaecology, An evidence-based Text for the MRCOG, $3^{\text {rd }}$ edition CRC Press Taylor and Francis Group Boca Raton London, New York; 2016:913-921.

2. Yakasai I, Abubakar I, Eze Y. Gestational Trophoblastic Diseases in Teaching Hospital in Northern Nigeria. American Journal of Bioscience. Vol.3. No.1. 2015: 710.

3. Dutta DC. Genital Malignancy. In: Konar H (ed). DC Dutta's Textbook of Gnaecology including contraception. Sixth edition. New Central Book Agency (P) Ltd, London; 2013; 333-392.

4. Kolawole AO, Nwajagu JK, Ogunta AO, Zayyan MS, Adewuyi S. Gestational Trophoblastic Disease in Ahmadu Bello University Teaching Hospital, Zaria, Nigeria. Tropical $\mathbf{J}$ of Obstetrics and Gynaecology. A Five-year Review. Vol.33, No.2, 2016: 209-215. 
5. Nyengidiki TK, Bassey G, Inimgba NM, Orazulike NC, Amadi C. A five year review of gestational trophoblastic diseases in Port Harcourt, Nigeria. Port Harcourt Medical Journal 2016; 10: 18-24.

6. Mbamara SU, Obiechina NJA, Eleje GU, Akabuike CJ, Umeononihu OS. Gestational trophoblastic disease in a tertiary hospital in Nnewi, Southeast Nigeria. Niger Med J 2009; 50:87-9.

7. Ocheke AN, Musa J, Uamai AO. Hydatidiform mole in Jos, Nigeria. Niger Med J, 2011: 52(4):223-226.

8. Aghajanian P. Gestational trophoblastic diseases. In: Decherney AH, Nathan L, Laufer N, Roman AS (eds). Current Diagnosis and Treatment Obstetrics and Gynecology, $11^{\text {th }}$ edition, Mc. Graw Hill, New York, 2013: 859-869.

9. Savage P. Gestational trophoblastic disease. In: Magowan BA. Owen P, Thomson A (eds). Clinical Obstetrics and Gynaecology, $3^{\text {rd }}$ edition, published by Saunders Elsvier, Edinburgh 2014: 159-164.

10. Eniola OA, Mabayoje P, Ogunniyi SO. Hydatidiform mole in Ile-Ife Nigeria. A 10year review J ObstetGynaecol. 2001; 21:405-407

11. Swanton A. Benign and malignant gynaecological conditions. In: Collins $\mathrm{S}$, Arulkumaran S, Hayes K, Jackson S, Impey L (eds). Oxford Handbook of Obstetrics and Gynaecology, $3^{\text {rd }}$ edition. Oxford University Press; 2003: 685-769.

12. Akinola OI, Nkyekyer K. Gestational Trophoblastic Disease. In: Kwawukume EY, Ekele BA, Danso KA, Emuveyan EE (eds) . Comprehensive Gynaecology in the Tropics, $2^{\text {nd }}$ edition. Designed and Printed by G-Pak Limited; 2017: 671-685.

13. Page RD, KudellaAp, Freedman RS, Kavanagh RJ. Gestational trophoblastic tumours. Medical Oncology: a comparative review $8^{\text {th }}$ ed. Oncology 2005.

14. Snyman LC. Gestational trophoblastic disease: An overview. SA Journal of Gynaecological Oncology 2009: Vol. 1 No.1.
15. Daniel CN, Ango IG, Nwobodo EI. Choriocarcinoma with cerebral metastasis presenting as stroke-like lesion. Sahel Med J 2015; 18, Suppl SI: 16-9

16. Audu BM, Takai IU, Chama CM, Bukar M, Kyari O. Hydatidiform mole as seen in a University Teaching Hospital: a 10 year review. J ObstetGynaecol, 2009 May; 29(4): 322-5

17. Igwebe AO, Eleje GU. Hydatidiform mole. A review of Management Outcomes in a tertiary Hospital in South-East Nigeria. Annals of medical and Health Sciences Research Apr-Jun 2013/V01 3/issue z/

18. Lakra P, Sangwan V, Siwach S, Kansal R, Mahendru R, Sharma A. Outcome of Gestational trophoblastic disease in rural tertiary center of Haryana, India Int J ReprodContraceptObstetGynaecol. 2017; Jan; 6(1): 271-275.

19. Adewole IF, Akinwuntan AA. Gestational trophoblastic Disease. In: Ikpeze OC (ed). Fundamentals of Obstetrics and Gynaecology, $1^{\text {st }}$ edition, Africana First Publishers Plc; 2009: 233-251.

20. Jimoh AAG, Ajayi AB, Saidu R. Hydatidiform mole in University of Ilorin Teaching Hospital: An 8 year Review. Int J of Tropical Med 2012; 7(2): 57-60.

21. Green Top Guideline No.38. London: RCOG; 2004. Royal College of Obstetricians and Gynaecologists. The Management of Gestational Trophoblastic Neoplasia.

22. Dauda AM, Akpor IO, Mandong BM, Ngbea J, Kwaghe BV, Emmanuel I. Prevalence of gestational trophoblastic disease: An institution experience. Ann Trop Pathol 2017;81-6

How to cite this article: Obetta HI, Hadiza AU , Nweze SO et.al. A five-year retrospective study of gestational trophoblastic disease at University of Maiduguri Teaching Hospital Maiduguri, Nigeria. International Journal of Science \& Healthcare Research. 2021; 6(2): 228-234. DOI: https://doi.org/ 10.52403/ijshr.20210441 